Review

\title{
Current Approaches and Challenges in Early Detection of Breast Cancer Recurrence
} \author{
Kirkpatrick ${ }^{1}$, Aviram Nissan², Leonard Henry ${ }^{3}$, Alexander Stojadinovic ${ }^{4}$, Nathan M. Shumway ${ }^{1}$, Itzhak \\ Avital $^{4}$, George E. Peoples ${ }^{1}$, and Robert F. Setlik ${ }^{1}$ \\ 1. San Antonio Military Medical Center (SAMMC), 3551 Roger Brooke Dr., Ft. Sam Houston, TX 78234, USA \\ 2. Hadassah Medical Center, Kiryat Hadassah, POB 12000, Jerusalem, 91120, Israel \\ 3. IU Health Goshen, 200 High Park Ave., Goshen, IN 46526, USA \\ 4. Bon Secours Cancer Institute, 5855 Bremo Road, Richmond, VA 23226, USA
}

Erika J. Schneble ${ }^{1}{ }^{\bowtie}$, Lindsey J. Graham ${ }^{1}$, Matthew P. Shupe ${ }^{1}$, Frederick L. Flynt ${ }^{1}$, Kevin P. Banks ${ }^{1}$, Aaron D.

$\square$ Corresponding author: Erika J. Schneble. Brooke Army Medical Center, Department of General Surgery, 3551 Roger Brooke Dr. Ft. Sam Houston, TX 78234. Office: 210-916-0439. Fax: 210-916-0439. Email: erika.j.schneble.mil@mail.mil

() Ivyspring International Publisher. This is an open-access article distributed under the terms of the Creative Commons License (http://creativecommons.org/ licenses/by-nc-nd/3.0/). Reproduction is permitted for personal, noncommercial use, provided that the article is in whole, unmodified, and properly cited.

Published: 2014.03.16

\begin{abstract}
Early detection of breast cancer recurrence is a key element of follow-up care and surveillance after completion of primary treatment. The goal is to improve survival by detecting and treating recurrent disease while potentially still curable assuming a more effective salvage surgery and treatment. In this review, we present the current guidelines for early detection of recurrent breast cancer in the adjuvant setting. Emphasis is placed on the multidisciplinary approach from surgery, medical oncology, and radiology with a discussion of the challenges faced within each setting.
\end{abstract}

Key words: Breast cancer; Recurrence; Adjuvant; Surveillance; Follow-up

\section{Introduction}

The current rise in breast cancer prevalence intensifies the global need for long-term surveillance programs [1]. This is a consequence of increased diagnosis from breast cancer screening programs and decreased disease-related mortality secondary to improved treatment modalities. This review discusses the current approaches and challenges of early detection of recurrent breast cancer after primary treatment.

After curative primary therapy, follow up of breast cancer patients focuses on early detection of recurrent disease when potentially still curable. Studies show detection of asymptomatic breast cancer recurrences by clinical screening carries a more favorable prognosis than patients presenting with symptomatic disease [2]. A recent meta-analysis of 2,263 breast cancer survivors from thirteen studies supports this hypothesis where the early detection group (asymptomatic recurrence found by mammography) exhibited superior survival in both the loco-regional and contra-lateral breast cancer recurrence groups compared to women who presented with symptoms due to recurrent cancer [3]. The authors were able to show the studies calculating follow up time from the date of recurrence had similar hazard ratios to those studies that calculated follow up time from the date of primary treatment of recurrence, suggesting the lead-time bias did not explain the effect on early detection.

The current standard of care for breast cancer follow-up requires a multi-disciplinary approach from radiologists, surgeons, and primary care physicians. At this time, surveillance for distant recurrence is not considered amenable to curative treatment or associated with a survival benefit $[4,5]$ and is thus not discussed in this review. The focus is the early detec- 
tion of loco-regional or contralateral recurrence with intent to improve long-term survival. The challenges faced while sustaining efficient and effective surveillance practices are evaluated after a review of the current guidelines.

\section{Surveillance Guidelines}

Current recommendations for breast cancer screening involve radiographic and clinical evaluations. Radiographic studies provide a non-invasive means to detect recurrent or new disease. Mammography is the mainstay of surveillance imaging following curative treatment of breast cancer with $8 \%-50 \%$ of ipsilateral recurrences and $18 \%-80 \%$ of contralateral metachronous cancers detected by mammography alone [6]. Most treatment guidelines, including the American Society of Clinical Oncology (ASCO) and the National Comprehensive Cancer Center Network (NCCN), suggest annual mammography following breast-conserving therapy $[7,8]$. This recommendation is based upon expert opinion as there are no adequate randomized controlled trials demonstrating mammography's benefit in the setting of surveillance.

Regular follow-up with a medical oncologist aims to identify new symptoms or changes on physical examination. Current NCCN guidelines recommend routine history and physical examination every 4 to 6 months for the first five years after primary therapy and annually thereafter [9]. ASCO, however, recommends routine history and physical examination every 3 to 6 months for first 3 years, every 6 to 12 months for years 4 and 5, then annually thereafter [8]. Both the NCCN and ASCO do not recommend the use of routine complete blood counts, chemistry panels, tumor markers, bone scans, computed tomography (CT) scans, magnetic resonance imaging (MRI) scans, positron-emission computed tomography (PET) scans, or ultrasound examinations in asymptomatic patients without specific clinical examination findings $[8,9]$. Dedicated breast MRI may be considered for post-therapy surveillance in women at high risk for bilateral disease, such as carriers of the BRCA $1 / 2$ mutations [9].

Identifying the optimal imaging modality for surveillance imaging remains a significant challenge. There are no randomized clinical trials evaluating the effectiveness of breast MRI, ultrasound, or positron-emission computed tomography (PET/CT) in the setting of breast cancer surveillance. As discussed below, supplemental imaging may be considered in symptomatic patients and patients at high risk for recurrent disease. The majority of literature regarding each modality is retrospective in nature. Thus, there is no definitive evidence to support any of these meth- ods as a primary imaging modality for surveillance [10].

Part of the challenge in early detection of recurrent disease after primary treatment is implementing effective strategies that safeguard optimal patient follow-up tracking and compliance while ensuring cost-effectiveness. Addressing these surveillance challenges is beyond the scope of this paper and will be discussed in a future review.

\section{Clinical Assessment}

The three tests usually considered for early detection in breast cancer screening include mammography, the clinical breast examination (CBE), and the self breast examination (SBE). Although data suggests recurrent disease detected by mammography correlates with increased survival [3], the utility of the SBE and CBE is debated despite continued recommendations by ASCO [11, 12] and NCCN [9]. These guidelines recommend periodic physical examination and CBE in addition to patient education of disease recurrence symptoms and SBE techniques to facilitate breast self-awareness [13].

Historically, most breast cancer recurrences are detected by the patient or clinician [14-16] with studies prior to 2000 reporting CBE detection rates of potentially treatable relapses as high as $46 \%$ [17]. However, the percentage of CBE-detected relapses has waned to approximately $15 \%$ in modern literature as experience with mammography grows [18-20]. The favor of CBE is largely as a safeguard against false negatives [21-24] with general screening mammography cited to miss $10-15 \%$ of palpable lesions $[25,26]$.

Although a benign and noninvasive intervention, the precision of the clinical assessment is limited by the multi-factorial nature of the breast examination. Estimates of breast examination sensitivity are dependent on a number of factors including the size of the lesion, individual breast characteristics, patient age, extent of follow-up to elucidate false negatives, and the skill of the examiner. For example, on a simulation-based assessment female examiners tend to display greater examination time and have a higher sensitivity compared to that of male counterparts [27]. Breast tissue heterogeneity also influences sensitivity where estimates of CBE detection on women aged 40-49 are approximately 10\% lower at initial screen compared to women aged 50-59 [28]. Conversely, SBE accuracy decreases with advanced age from approximately $41 \%$ in women aged $35-39$ to $21 \%$ in women aged 60-74 [29] with overall detection rates from $12 \%$ to $40 \%[20,30]$. The greatest challenge of both the CBE [24] and SBE [22, 31], regardless of age, is the detection of benign breast lesions leading to unnecessary invasive procedures. 
The overall impact of clinical examinations on survival remains questionable. Although early detection of asymptomatic relapse is known to increase survival $[32,33]$, it is uncertain whether clinical examinations contribute to this benefit. SBE-detected cancer recurrences, in addition to mammographically detected lesions, are correlated with increased survival $[3,20,34]$. However, modern systematic literature reviews suggest no mortality benefit of CBE-detected relapses. Instead, patients may in fact have poorer outcomes than those whose relapse is diagnosed by SBE or mammography $[17,18,20]$.

Overall, the precision of CBE and SBE is challenged by patient heterogeneity and lack of consistent and standardized examination techniques [24]. Efforts to increase early disease detection by increased frequency of clinical exams can result in increased false-positive tests with unnecessary, and likely more invasive diagnostic tests, increased healthcare costs, and heightened patient anxiety [35] without an associated mortality benefit. Clinical screening, particularly the $\mathrm{CBE}$, requires the development of new techniques and protocols for greater standardization and precision for the detection of breast cancer relapses to be discussed in a subsequent review.

\section{Laboratory Assessment}

In addition to imaging and clinical examination, many oncologists employ the use of circulating serum tumor markers to predict relapse. Current ASCO guidelines state that there is insufficient evidence to support using circulating tumor markers such as CA 15-3 and CA 27-29, or carcinoembryonic antigen (CEA) to monitor for disease recurrence after primary therapy $[11,36]$. It is important to note that this recommendation does not apply to monitoring disease in the metastatic setting, where the use of serum tumor markers is not discouraged. Although these markers may predict disease recurrence months in advance, there is no evidence showing subsequent improvements in survival or quality of life in the adjuvant (non-metastatic) setting. Multiple studies have assessed the use of tumor markers for monitoring for recurrence of disease. Some of these are listed in Table 1.

Table I: Summaries from Recent Studies Using Serum Tumor Markers to Monitor for Recurrence in the Adjuvant Setting

\begin{tabular}{|c|c|c|c|}
\hline Reference & Patients & Intervention & Outcome \\
\hline Zervoudis (2007)[40] & $\begin{array}{l}358 \text { patients with stage I } \\
\text { breast cancer who were } \\
\text { disease free after primary } \\
\text { treatment. }\end{array}$ & $\begin{array}{l}\text { Clinical exam, mammography, } \\
\text { bone scintigraphy, annual CT of } \\
\text { the chest and abdomen and } \\
\text { multiple serum tumor markers } \\
\text { including CEA, CA 15-3, CA } \\
27-29 \text { every } 4 \text { months }\end{array}$ & $\begin{array}{l}18 \text { patients }(5 \%) \text { had increased tumor markers by } \\
\text { cutoff values. All of them had negative workup for } \\
\text { disease. } \\
\text { After } 5 \text { years of follow up, } 15 \text { of those } 18 \text { patients } \\
\text { remained free of local recurrence or metastatic dis- } \\
\text { ease and the other } 3 \text { were lost to follow up. }\end{array}$ \\
\hline Nicolini (2006)[41] & $\begin{array}{l}268 \text { breast cancer patients } \\
\text { that were disease free at the } \\
\text { start of the study. All stages } \\
\text { seem to have been repre- } \\
\text { sented and were treated } \\
\text { according to guidelines. }\end{array}$ & $\begin{array}{l}\text { Serial serum CEA, CA 15-3, TPA, } \\
\text { MCA were measured every 4-6 } \\
\text { months. } \\
\text { Bone scan, liver ultrasound, and } \\
\text { chest } x \text { ray were performed } \\
\text { every } 24-36 \text { months to detect any } \\
\text { false negatives. }\end{array}$ & $\begin{array}{l}\text { There were } 19 \text { relapses. Mean lead times between } \\
\text { tumor marker elevation and the appearance of dis- } \\
\text { ease were between about 3-7 months depending on } \\
\text { the tumor marker } \\
\text { Sensitivities ranged from } 10-68 \% \text {. } \\
222 \text { patients were found to have tumor marker ele- } \\
\text { vations for non-malignant reasons leading to speci- } \\
\text { ficities around } 40-70 \%\end{array}$ \\
\hline Valenzuela (2002)[42] & $\begin{array}{l}318 \text { patients who were dis- } \\
\text { ease-free after primary } \\
\text { therapy }\end{array}$ & $\begin{array}{l}\text { CA } 15.3 \text { and CEA were meas- } \\
\text { ured in serum at each routine } \\
\text { follow up visit }\end{array}$ & $\begin{array}{l}59 \text { patients relapsed, } 28 \text { of whom had elevated CA } \\
15-3 \text { levels and } 31 \text { of whom did not. } \\
30 \text { patients had false positive elevations of CA 15-3. } \\
17 \text { patients had elevated tumor markers (16 CA 15-3 } \\
\text { and } 1 \text { CEA) before clinical appearance of metastases. }\end{array}$ \\
\hline Pedersen (2013)[43] & $\begin{array}{l}9 \text { patients with local recur- } \\
\text { rence and } 83 \text { patients who } \\
\text { developed distant metasta- } \\
\text { ses after primary treatment. } \\
\text { Patients who originally pre- } \\
\text { sented with distant metasta- } \\
\text { ses were excluded. }\end{array}$ & $\begin{array}{l}\text { CA 15-3, CEA, and HER2 were } \\
\text { measured. A result was consid- } \\
\text { ered positive if above a certain } \\
\text { threshold. }\end{array}$ & $\begin{array}{l}\text { None of the patients with local recurrence had ele- } \\
\text { vated serum tumor markers. } \\
\text { The most sensitive marker to detect recurrence was } \\
\text { CA } 15-3(49.4 \%) \text {. } \\
\text { The most sensitive combination was CA } 15-3 \text { and } \\
\text { CEA }(60.2 \%) \\
\text { In patients with HER } 2+\text { tumors, the sensitivity of } \\
\text { serum HER } 2 \text { was } 55.6 \% \text { and } 21.2 \% \text { in patients with } \\
\text { HER } 2 \text { negative tumors }\end{array}$ \\
\hline
\end{tabular}

CEA = carcinoembryonic antigen, MCA = mucin-like carcinoma associated antigen, TPA = tissue polypeptide. Of note, each study used different cutoff values for identifying a patient as positive, though all followed trends in this marker. 
CA 15-3 and CA 27-29 are two separate assays that test for the same secreted mucin glycoprotein coded by the MUC1 gene. These assays are regarded as equivalent in their ability to detect the protein in serum [37]. MUC1 derived glycoprotein is aberrantly over-expressed in human breast cancer and can even antagonize the inhibitory effects of tamoxifen [38].

The human epidermal growth factor receptor 2 (HER2) has an extracellular domain, a transmembrane domain, and an intracellular domain. The extracellular domain (ECD) may be cleaved from the receptor and sent into circulation where it can be measured by the use of an immunoassay. Though more commonly used in the metastatic setting, it has been studied in the adjuvant setting as well to monitor recurrence [39]. Table 1 shows some of the recent studies exploring the use of serum tumor markers in the adjuvant setting to detect recurrence.

One of the challenges with the use of serum tumor markers is what to do with a positive marker in the setting of no radiographic evidence of disease. Early rises in markers may increase patient anxiety and lead to unnecessary testing and increased cost of care [4]. One potential way to enhance the effectiveness of tumor markers is to limit their use to those women at highest risk of relapse. In addition, molecular identification of breast cancer subtypes may also help determine the usefulness of different markers of disease recurrence. This shift towards personalized disease monitoring may improve the utility of serum tumor markers.

The current challenge of post-treatment follow up is to best predict which patients are at increased risk of recurrence and then explore the best surveillance strategy in those patients. At present, guidelines recommend estrogen receptor (ER), progesterone receptor (PgR), and HER2 expression testing to guide treatment decisions - namely the use of hormonal therapy and traztuzumab, respectively [36]. However, newer assays employing microarray technology may help provide both predictive and prognostic information. Current technology employs gene expression profiling such as the 21 gene expression test (Oncotype $\mathrm{DX}^{\mathrm{TM}}$ ) and 70 gene microarray test (MammaPrint ${ }^{\circledR}$ ) and to better understand the molecular biology of individual breast cancer. In the accompanying article, we will discuss how this newer technology can be used to enhance the monitoring of occult disease.

\section{Radiologic assessment}

Over the past 20 to 30 years, improved screening and treatment strategies for breast cancer have contributed to significant decreases in breast cancer-related mortality. Breast-conserving surgery fol- lowed by radiation therapy results in similar survival outcomes as mastectomy, with local recurrence in the ipsilateral breast occurring 6-9\% at 5 years and $14-20$ $\%$ at 20 years [44]. Per the American Cancer Society (ACS) and the American College of Radiology (ACR) guidelines, this risk stratifies a woman with a personal history of breast cancer (excluding other risk factors) is considered intermediate risk (15-20\% lifetime risk). The majority of literature supports the premise that early detection of asymptomatic local recurrence via appropriate surveillance techniques, to include breast imaging, improves long-term survival when compared to late symptomatic detection [3, 44, 45]. Therefore, sensitive, non-invasive, and cost-effective surveillance strategies to detect early local recurrence are necessary.

\section{Mammography}

Mammography is the mainstay of surveillance imaging following curative treatment of breast cancer with $8 \%-50 \%$ of ipsilateral recurrence and $18 \%-80 \%$ of contralateral metachronous cancer detected by mammography alone [6]. Most clinical guidelines suggest patients obtain their first post-treatment mammogram "1 year after the initial mammogram leading to diagnosis, but no earlier than 6 months after definitive radiation therapy" [11]. However, as stated above, recommendations for surveillance mammography are based upon expert opinion as there are no adequate randomized controlled trials demonstrating mammography's benefit in this setting. Most researchers agree that regular surveillance mammography in women diagnosed with early stage breast cancer improves long-term outcomes; however, the optimal interval for mammographic follow-up is currently debated. Some studies suggest benefit from biannual mammography in the initial 2-5 years following treatment, while other studies and most major treatment guidelines (including ASCO and NCCN) support annual mammography following breast conservation therapy [6, 46, 47]. One retrospective study and a meta-analysis of surveillance mammography found no benefit to semi-annual (6-month interval) screening mammography, while a recent retrospective single-institution review suggests a benefit from 5 years of semiannual mammographic surveillance $[6,48-50]$.

\section{Supplemental Screening Modalities}

Identifying the optimal imaging modality for surveillance imaging remains a significant challenge as there are no randomized clinical trials evaluating the effectiveness of breast MRI, ultrasound, or PET/CT in the setting of breast cancer surveillance. The majority of literature regarding each modality is 
retrospective in nature. Thus, there is no definitive evidence to support any of these methods as a primary imaging modality for surveillance. Currently there is no ideal single modality for imaging surveillance that is non-invasive, cost effective, and has the appropriate balance of sensitivity and specificity. Although mammography is able to detect $25-45 \%$ of recurrences, the post-operative and post-radiation changes of breast conservation therapy decrease mammography's sensitivity and specificity compared with a standard screening population $[44,51]$. Thus, the role of other breast imaging modalities as an adjunct screening tool to mammography and clinical examination is an active area of investigation.

\section{Ultrasound}

Neither the NCCN, nor the ASCO guidelines directly recommend supplementary screening with ultrasound [11, 52]. The ACR suggests considering supplemental ultrasography as an option in women with intermediate risk (to include those with a personal history of breast cancer) and dense breasts.[10] Furthermore, ultrasound is a useful option for high risk women who are not candidates for breast MRI [3, $44,45,53]$. Berg et al recently demonstrated that an annual supplemental screening ultrasound in intermediate and high-risk women with mammographically dense breasts detects an additional 3.7 cancers per 1000 women screened $[6,54]$. The majority of ultrasound-detected mammographically-occult breast cancers are small and node-negative [11, 55].

Although supplemental screening with ultrasound may detect mammographically-occult cancers, its role in the early detection of breast cancer is not well defined. Multiple independent studies evaluation intermediate to high-risk populations demonstrate that the combination screening mammography with supplemental ultrasound resulted in a higher false-positive rate and a lower positive predictive value when compared to screening mammography alone $[6,46,47,56]$. Furthermore, in-situ cancers are often missed by sonography, and screening ultrasound is time intensive - often requiring direct physician supervision. There is no prospective outcome study demonstrating improved mortality rates through supplemental screening ultrasonography; which would require a large multicenter prospective trial. If supplemental screening ultrasonography is to become standard of care, then future studies will need to demonstrate a reduction in false positive results and appropriate utilization of resources. Currently, the primary role of ultrasound is in the evaluation of symptomatic patients $[10,52]$.

\section{Breast MRI}

The post-procedural and post-therapy changes of breast conservation therapy limit the sensitivity of mammography and ultrasound for detection of recurrence [6, 48-50,57]. Multiple studies demonstrate high sensitivity and specificity for breast MRI in the detection of local recurrences [54, 58-61]. It also has high sensitivity, specificity, and accuracy in differentiating post-operative scar from recurrent tumor [62]. While breast MRI is superior to other modalities as a single option, it is expensive, resource intensive and frequently less tolerable for patients than mammography or ultrasound $[54,56]$.

The ACR practice guidelines for breast MR state that MRI is useful in women with a history of breast cancer and suspicion for disease recurrence when clinical, mammographic, or sonographic findings are inconclusive [49]. Similarly, an ACS panel concluded that the increased risk of local recurrence of contralateral metachronous disease in a woman with a personal history of breast cancer alone does not justify a recommendation for screening MRI after breast conservation therapy [63]. Recently, Brennan and colleagues identified 17 carcinomas in 144 women (12\%) with personal history of breast cancer, but no family history - 10 of these cancers were mammographically occult and the positive predictive value of biopsy was $39 \%$ [64]. A separate study by Berg, et al demonstrated that supplemental MRI was less likely to prompt unnecessary recall or biopsy in women with a personal history of breast cancer than in those without a personal history of breast cancer [54]. Thus, the choice of adjunct surveillance with Breast MRI in women with a personal history of breast cancer is still under investigation and further studies for optimal patient selection are needed.

Annual screening MRI as an adjunct to mammography and clinical breast exam is recommended for certain high risk populations. This includes women 25 years or older with a genetic predisposition, such as known BRCA 1/BRCA 2 positivity, a greater than $20 \%$ lifetime risk for developing breast cancer as defined by various risk stratification models, and for women with a family history suggesting a genetic predisposition for breast cancer [10, 52]. A significant family history includes having 2 or more first-degree relatives with breast cancer, a first-degree relative with premenopausal breast cancer, a family history of breast and ovarian cancer, a first-degree relative with more than one independent cancer, and having a male relative with breast cancer. The NCCN guidelines also recommend consideration of annual MRI in women diagnosed with lobular carcinoma in situ (LCIS) and in women 25 years or older with a 
history of chest irradiation beginning at age 40 or 8 to 10 years after radiation exposure.

\section{Post-Mastectomy Imaging}

Another significant challenge is identifying the appropriate algorithm and modality for surveillance in the post-mastectomy population. There are no definitive guidelines for surveillance in patients treated by mastectomy with or without reconstruction. Chest wall recurrence in mastectomy patients is between $5 \%$ and $30 \%[59,61]$. Case reports and retrospective reviews demonstrate that local recurrence can be detected by surveillance mammography in women with breast reconstruction following mastectomy, but no clear evidence exists to support or discourage routine imaging surveillance in this particular patient population [59, 61, 65]. Currently, surveillance imaging algorithms are institutional dependent.

\section{Other Imaging Modalities}

As previously discussed, mammography is the only imaging modality universally recommended for surveillance of women with a history of breast cancer [11]. Molecular imaging studies such as bone scans or FDG (fluorodeoxyglucose) PET-CT are currently not indicated in an otherwise asymptomatic patient without specific clinical complaints or findings on physical examination. Unlike MRI or US, this holds true even for women with a personal history of breast cancer or high risk for breast cancer. This position is based primarily upon two large randomized prospective trials performed in the early 1990's as well as a more recent systematic review of studies comparing the outcome of patients followed with mammography and clinical examinations, with those followed using an intense regimen of imaging and laboratory testing. Each study found no survival benefit or improvement in quality of life associated with the more comprehensive follow-up $[5,66,67]$. Critics of this approach argue these studies were based upon older and less sensitive imaging tests (i.e. did not include FDG PET or PET-CT) and did not have the advantage of newer therapies such as aromatase inhibitors [68].

Once recurrent disease is suspected, FDG PET is very effective in confirming the presence or absence of disease and accurately assessing its extent. Two retrospective studies showed a sensitivity of $92-97 \%$, an accuracy of $87-90 \%$, and a specificity ranging from $75-82 \%$ for FDG PET predicting recurrent disease[69, 70]. PET-CT has shown even more effective in assessing recurrent breast cancer as well as many other malignancies [71]. In an evaluation of thirty-four patients with suspected breast cancer, PET-CT demonstrated a significant increase in sensitivity and specificity $(96 \%$ versus $88 \%$ and $89 \%$ versus $78 \%$ respectively) compared with PET alone. In one of the largest studies to date, a review of 228 symptomatic patients with rising serum CA 15-3 and/or CEA levels, FDG PET-CT demonstrated a sensitivity of $94 \%$ and specificity of $85 \%$ with an accuracy of $92 \%$ [72]. This same study compared FDG PET-CT to conventional imaging techniques (contrast-enhanced CT, abdominal ultrasound, chest x-ray and/or bone scan) in a subset of 67 women and reaffirmed the superior sensitivity (95\% versus $33 \%$ ) and accuracy (94\% and $48 \%$ ) of PET-CT. Many smaller studies confirm these results (Table 2).

Table 2: Review of PET-CT in Assessment of Women with a History of Breast Cancer and Suspected Recurrence

\begin{tabular}{|c|c|c|c|c|c|c|c|}
\hline Lead Author & Year & $\# \mathrm{Pt}$ & Sens & Spec & Accuracy & $\begin{array}{l}\text { \% Change } \\
\text { Mgmt }\end{array}$ & Comparison \\
\hline Champion[72] & 2011 & 228 & $94 \%$ & $85 \%$ & $92 \%$ & $54 \%$ & Conventional WU \\
\hline Evangelista[68] & 2011 & 111 & $81 \%$ & $52 \%$ & $60 \%$ & $56 \%$ & Conventional WU \\
\hline Grassetto [73] & 2010 & 89 & NR & NR & NR & $45 \%$ & Conventional WU \\
\hline Fueger [74] & 2005 & 58 & $94 \%$ & $84 \%$ & $90 \%$ & NR & PET \\
\hline Aukema [75] & 2010 & 56 & $97 \%$ & $92 \%$ & $95 \%$ & $48 \%$ & Conventional WU \\
\hline Dirisamer [76] & 2009 & 52 & $93 \%$ & $100 \%$ & NR & NR & CECT \\
\hline Filippi [77] & 2011 & 46 & $87 \%$ & $88 \%$ & $87 \%$ & $50 \%$ & \\
\hline Radan [78] & 2006 & 46 & $90 \%$ & $71 \%$ & $80 \%$ & $51 \%$ & CECT \\
\hline Haug [79] & 2007 & 34 & $96 \%$ & $89 \%$ & NR & NR & CECT \\
\hline Schmidt [80] & 2008 & 33 & $91 \%$ & $90 \%$ & NR & NR & WB MRI \\
\hline
\end{tabular}

$\mathrm{WU}=$ work up $\mathrm{CECT}=$ contrast enhanced $\mathrm{CT}, \mathrm{WB}=$ whole body

In addition to FDG PET-CT, two other molecular imaging modalities are available for the assessment of breast cancer recurrence. Both are helpful in the setting of skeletal relapse. Tc99m-disphosphonate bone scanning (BS) and 18F-Sodium Fluoride (NaF)
PET/PET-CT are useful for imaging osseous metastases based upon the lesions' increased blood flow and pathologic osteoblastic activity. Bone scintigraphy has been shown to be particularly useful given its ability to evaluate the entire skeleton, with a good 
diagnostic sensitivity of $87-88 \%$ in the assessment of patients with breast cancer bone metastases [81]. Though false-positive results can be seen due to degenerative disease, trauma, and other benign entities, its specificity can be appreciably improved through the use of SPECT (single-photon emission computed tomography) or SPECT-CT as well as correlative imaging [82]. It should be noted though that FDG PET-CT is as good as or better than bone scintigraphy in the detection and characterization of bone metastases. While early studies showed FDG PET to have a lower rate of detection than bone scintigraphy for osteoblastic lesions (but similar for mixed and osteolytic lesions) [83], a meta-analysis of 4 prospective and 2 retrospective studies found similar patient-based sensitivity $(81 \%$ and $78 \%$ for PET-CT and BS respectively) and better patient and lesion-based specificity with FDG PET-CT when compared to bone scintigraphy (98\% vs. $87 \%$ ) [81]. These authors suggested that bone scintigraphy's improved lesion-based sensitivity may simply be due to the modality's increased field of view (all of the extremities and skull which are often not included in a standard 'whole-body' PET-CT). Given these findings, only one or the other modality is generally suitable as the sole means for assessing the presence and extent of bone metastases.

In contrast to BS and FDG PET-CT, $18 \mathrm{~F}-\mathrm{NaF}$ PET-CT has clearly shown superior sensitivity for the detection of bone metastases in patients with breast cancer and other malignancies. In a very recent study of 151 patients with various cancers, 72 of which had a history of invasive ductal carcinoma, Fluoride PET-CT was much more sensitive and had a greater negative predictive value regarding the presence of skeletal disease $(100 \%$ sensitivity and negative predictive value vs. $73 \%$ and $80 \%$ for FDG PET-CT and similar outperformance versus bone scintigraphy) [84]. Other investigators have shown the same superiority of NaF PET-CT [85]. Thus, if there is a high index of suspicion for isolated skeletal metastases, NaF PET-CT may be the optimal choice.

There is insufficient evidence for the use of other modalities such as thermography, breast-specific gamma imaging, positron emission mammography, and optical imaging for breast cancer screening. Although patients and healthcare providers often prefer intensive screening and follow-up after a diagnosis of breast cancer, aside from annual mammography, the routine use of advanced imaging to evaluate for recurrence and/or metastatic disease does not result in increased survival or improved quality of life. There is little evidence to justify routine imaging with $\mathrm{CT}$, MRI, radiography, or nuclear medicine studies for the detection of metastasis in asymptomatic women.

\section{Future Directions and Challenges}

Digital breast tomosynthesis (DBT) is an emerging modality with early clinical studies showing promising results. The potential use of DBT, contrast enhanced mammography, and molecular imaging as future modalities in breast cancer screening will be discussed in a separate manuscript.

\section{Conclusion}

Breast cancer relapses are rarely curable with estimates of only $1-1.5 \%$ of women who present each year with recurrent breast cancer having potentially curable disease $[17,20]$. However, current data shows a survival benefit from early detection of asymptomatic loco-regional or contra-lateral breast cancer recurrences [3]. With as many as $40 \%$ of isolated loco-regional recurrences asymptomatic at the time of detection [86], the question remains how to solve surveillance challenges to increase this percentage. A multi-disciplinary approach requiring close collaboration between radiologists, medical oncologists, and surgeons is necessary. Surveillance techniques within each setting should strive for improved patient survival with attention to quality of life. Non-essential interventions cause increased patient anxiety, unnecessary testing, and increased cost of care and utilization of resources. Future strategies that optimize disease detection while maximizing patient well-being, resource utilization, and efficiency are to be discussed in a subsequent review.

\section{Abbreviations}

ASCO: American Society of Clinical Oncology; NCCN: National Comprehensive Cancer Center Network; CT: computed tomography; MRI: magnetic resonance imaging; PET: positron-emission tomography; PET/CT: positron-emission computed tomography; CBE: clinical breast examination; SBE: self breast examination; CEA: carcinoembryonic antigen; HER2: human epidermal growth factor receptor 2; ECD: extracellular domain; ER: estrogen receptor; PgR: progesterone receptor; ACS: American Cancer Society; ACR: American College of Radiology; LCIS: lobular carcinoma in situ; BS: bone scanning; NaF: Sodium Fluoride; DBT: digital breast tomosynthesis; FDG: fluorodeoxyglucose; SPECT: single-photon emission computed tomography

\section{Competing Interests}

The authors have declared that no competing interest exists. 


\section{References}

1. Parkin DM, Fernandez LM. Use of statistics to assess the global burden of breast cancer. The breast journal. 2006; 12 Suppl 1: S70-80. doi:10.1111/j.1075-122X.2006.00205.x.

2. van der Sangen MJ, Poortmans PM, Scheepers SW, Lemaire BM, van Berlo CL, Tjan-Heijnen VC, et al. Prognosis following local recurrence after breast conserving treatment in young women with early breast cancer. Eur J Surg Oncol. 2013; 39: 892-8. doi:S0748-7983(13)00375-2 [pii]10.1016/j.ejso.2013.05.004.

3. Lu WL, Jansen L, Post WJ, Bonnema J, Van de Velde JC, De Bock GH. Impact on survival of early detection of isolated breast recurrences after the primary treatment for breast cancer: a meta-analysis. Breast Cancer Res Treat. 2009; 114: 403-12. doi:10.1007/s10549-008-0023-4.

4. Rosselli Del Turco M, Palli D, Cariddi A, Ciatto S, Pacini P, Distante V. Intensive diagnostic follow-up after treatment of primary breast cancer. A randomized trial. National Research Council Project on Breast Cancer follow-up. JAMA. 1994; 271: 1593-7.

5. Investigators TG. Impact of follow-up testing on survival and health-related quality of life in breast cancer patients. A multicenter randomized controlled trial. The GIVIO Investigators. JAMA. 1994; 271: 1587-92.

6. Arasu VA, Joe BN, Lvoff NM, Leung JW, Brenner RJ, Flowers CI, et al. Benefit of semiannual ipsilateral mammographic surveillance following breast conservation therapy. Radiology. 2012; 264: 371-7. doi:10.1148/radiol.12111458

7. Carlson RW, Allred DC, Anderson BO, Burstein HJ, Carter WB, Edge SB, et al. Breast Cancer. Journal of the National Comprehensive Cancer Network. 2009; 7: 122-92.

8. Khatcheressian J, Hurley P, Bentug E, Esserman LJ, Grunfeld E, Halberg F. Breast Cancer Follow-Up and Management After Primary Treatment: American Society of Clinical Oncology Clinical Practice Guideline Update. Journal of Clinical Oncology. 2013; 31: 961-5.

9. NCCN. NCCN Clinical Practice Guidelines in Oncology (NCCN Guidelines): breast cancer-version 3.2013. 2013.

10. Lee CH, Dershaw DD, Kopans D, Evans P, Monsees B, Monticciolo D, et al. Breast Cancer Screening With Imaging: Recommendations From the Society of Breast Imaging and the ACR on the Use of Mammography, Breast MRI, Breast Ultrasound, and Other Technologies for the Detection of Clinically Occult Breast Cancer. Journal of the American College of Radiology. 2010; 7: 18-27.

11. Khatcheressian JL, Hurley P, Bantug E, Esserman LJ, Grunfeld E, Halberg F, et al. Breast cancer follow-up and management after primary treatment: American Society of Clinical Oncology clinical practice guideline update. J Clin Oncol. 2013; 31: 961-5. doi:10.1200/JCO.2012.45.9859.

12. Smith TJ, Davidson NE, Schapira DV, Grunfeld E, Muss HB, Vogel VG, 3rd, et al. American Society of Clinical Oncology 1998 update of recommended breast cancer surveillance guidelines. J Clin Oncol. 1999; 17: 1080-2.

13. Bevers TB. Breast awareness: a shift in the paradigm of breast self-examination. J Natl Compr Canc Netw. 2009; 7: 1042-3.

14. Tomin R, Donegan WL. Screening for recurrent breast cancer--its effectiveness and prognostic value. J Clin Oncol. 1987; 5: 62-7.

15. Scanlon EF, Oviedo MA, Cunningham MP, Caprini JA, Khandekar JD, Cohen E, et al. Preoperative and follow-up procedures on patients with breast cancer. Cancer. 1980; 46: 977-9.

16. Schapira DV, Urban N. A minimalist policy for breast cancer surveillance. JAMA. 1991; 265: 380-2.

17. Montgomery DA, Krupa K, Cooke TG. Alternative methods of follow up in breast cancer: a systematic review of the literature. Br J Cancer. 2007; 96: 1625-32. doi:10.1038/sj.bjc.6603771.

18. Montgomery DA, Krupa K, Jack WJ, Kerr GR, Kunkler IH, Thomas J, et al. Changing pattern of the detection of locoregional relapse in breast cancer: the Edinburgh experience. Br J Cancer. 2007; 96: 1802-7. doi:10.1038/sj.bjc.6603815.

19. van der Sangen MJ, van de Poll-Franse LV, Roumen RM, Rutten HJ, Coebergh JW, Vreugdenhil G, et al. The prognosis of patients with local recurrence more than five years after breast conservation therapy for invasive breast carcinoma. Eur J Surg Oncol. 2006; 32: 34-8. doi:10.1016/j.ejso.2005.10.005.

20. Montgomery DA, Krupa K, Cooke TG. Follow-up in breast cancer: does routine clinical examination improve outcome? A systematic review of the literature. Br J Cancer. 2007; 97: 1632-41. doi:10.1038/sj.bjc.6604065.

21. McDonald S, Saslow D, Alciati MH. Performance and reporting of clinical breast examination: a review of the literature. CA Cancer J Clin. 2004; 54: 345-61.

22. Smith RA, Saslow D, Sawyer KA, Burke W, Costanza ME, Evans WP, 3rd, et al. American Cancer Society guidelines for breast cancer screening: update 2003. CA Cancer J Clin. 2003; 53: 141-69.

23. Force USPST. Screening for breast cancer: US Preventive Services Task Force recommendation statement. Ann Intern Med. 2009; 151: 716-26. doi:10.7326/0003-4819-151-10-200911170-00008.

24. Saslow D, Hannan J, Osuch J, Alciati MH, Baines C, Barton M, et al. Clinical breast examination: practical recommendations for optimizing performance and reporting. CA Cancer J Clin. 2004; 54: 327-44.

25. Barton MB, Harris R, Fletcher SW. The rational clinical examination. Does this patient have breast cancer? The screening clinical breast examination: should it be done? How? JAMA. 1999; 282: 1270-80. doi:jrc90000 [pii].

26. Griffin JL, Pearlman MD. Breast cancer screening in women at average risk and high risk. Obstet Gynecol. 2010; 116: 1410-21. doi:10.1097/AOG.0b013e3181fe714e.
27. Pugh CM, Domont ZB, Salud LH, Blossfield KM. A simulation-based assessment of clinical breast examination technique: do patient and clinician factors affect clinician approach? American journal of surgery. 2008; 195: 874-80. doi:10.1016/j.amjsurg.2007.10.018

28. Baines CJ, Miller AB, Bassett AA. Physical examination. Its role as a single screening modality in the Canadian National Breast Screening Study. Cancer. 1989; 63: 1816-22.

29. O'Malley MS, Fletcher SW. US Preventive Services Task Force. Screening for breast cancer with breast self-examination. A critical review. JAMA. 1987; 257: 2196-203.

30. Fletcher SW, Black W, Harris R, Rimer BK, Shapiro S. Report of the International Workshop on Screening for Breast Cancer. J Natl Cancer Inst. 1993; 85: 1644-56.

31. Thomas DB, Gao DL, Ray RM, Wang WW, Allison CJ, Chen FL, et al. Randomized trial of breast self-examination in Shanghai: final results. J Natl Cancer Inst. 2002; 94: 1445-57.

32. Haffty BG, Fischer D, Beinfield M, McKhann C. Prognosis following local recurrence in the conservatively treated breast cancer patient. Int J Radiat Oncol Biol Phys. 1991; 21: 293-8.

33. Dalberg K, Mattsson A, Sandelin K, Rutqvist LE. Outcome of treatment for ipsilateral breast tumor recurrence in early-stage breast cancer. Breast Cancer Res Treat. 1998; 49: 69-78.

34. Taggart F, Donnelly P, Dunn J. Options for early breast cancer follow-up in primary and secondary care - a systematic review. BMC Cancer. 2012; 12: 238. doi:1471-2407-12-238 [pii] 10.1186/1471-2407-12-238.

35. Paradiso A, Nitti P, Frezza P, Scorpiglione N. A survey in Puglia: the attitudes and opinions of specialists, general physicians and patients on follow-up practice. G.S.Bio.Ca.M. Ann Oncol. 1995; 6 Suppl 2: 53-6.

36. Harris L, Fritsche H, Mennel R, Norton L, Ravdin P, Taube S, et al. American Society of Clinical Oncology 2007 update of recommendations for the use of tumor markers in breast cancer. J Clin Oncol. 2007; 25: 5287-312. doi:JCO.2007.14.2364 [pii] 10.1200/JCO.2007.14.2364.

37. Klee GG, Schreiber WE. MUC1 Gene-Derived Glycoprotein Assays for Monitoring Breast Cancer (CA 15-3, CA 27.29, BR). Arch Pathol Lab Med. 2004; 128: 1131-5.

38. Kufe DW. Mucins in cancer: function, prognosis, and therapy. Nat Rev Cancer. 2009; 9: 874-85.

39. Sorensen PD, Jakobsen EH, Madsen JS, Petersen EB, Andersen RF, Ostergaard $B$, et al. Serum HER-2: sensitivity, specificity, and predictive values for detecting metastatic recurrence in breast cancer patients. J Cancer Res Clin Oncol. 2013; 139: 1005-13. doi:10.1007/s00432-013-1411-7.

40. Zervoudis S, Peitsidis P, Iatrakis G, Panourgias E, Koureas A, Navrozoglou I, et al. Increased levels of tumor markers in the follow-up of 400 patients with breast cancer without recurrence or metastasis: interpretation of false-positive results. J BUON. 2007; 12: 487-92.

41. Nicolini A, Tartarelli G, Carpi A, Metelli MR, Ferrari P, Anselmi L, et al. Intensive post-operative follow-up of breast cancer patients with tumour markers: CEA, TPA or CA15.3 vs MCA and MCA-CA15.3 vs CEA-TPA-CA15.3 panel in the early detection of distant metastases. BMC Cancer. 2006; 6: 269. doi:1471-2407-6-269 [pii] 10.1186/1471-2407-6-269.

42. Valenzuela P, Mateos S, Tello E, Lopez-Bueno MJ, Garrido N, Gaspar MJ. The contribution of the CEA marker to CA 15.3 in the follow-up of breast cancer. Eur J Gynaecol Oncol. 2003; 24: 60-2.

43. Pedersen AC, Sorensen PD, Jacobsen EH, Madsen JS, Brandslund I. Sensitivity of CA 15-3, CEA and serum HER2 in the early detection of recurrence of breast cancer. Clin Chem Lab Med. 2013;: 1-9.

44. Clarke M, Collins R, Darby S, Davies C, Elphinstone P, Evans E, et al. Effects of radiotherapy and of differences in the extent of surgery for early breast cancer on local recurrence and 15-year survival: an overview of the randomised trials. Lancet. 2005; 366: 2087-106. doi:10.1016/S0140-6736(05)67887-7.

45. Houssami N, Ciatto S. Mammographic surveillance in women with a personal history of breast cancer: how accurate? How effective? Breast. 2010; 19: 439-45. doi:10.1016/j.breast.2010.05.010.

46. Gunia SR, Merrigan TL, Poulton TB, Mamounas EP. Evaluation of appropriate short-term mammographic surveillance in patients who undergo breast-conserving Surgery (BCS). Ann Surg Oncol. 2012; 19: 3139-43. doi:10.1245/s10434-012-2578-x.

47. Lin K, Eradat J, Mehta NH, Bent C, Lee SP, Apple SK, et al. Is a short-interval postradiation mammogram necessary after conservative surgery and radiation in breast cancer? Int J Radiat Oncol Biol Phys. 2008; 72: 1041-7. doi:10.1016/j.ijrobp.2008.02.017

48. McNaul D, Darke M, Garg M, Dale P. An evaluation of post-lumpectomy recurrence rates: is follow-up every 6 months for 2 years needed? J Surg Oncol. 2013; 107: 597-601. doi:10.1002/jso.23298

49. Lee CH, Dershaw DD, Kopans D, Evans P, Monsees B, Monticciolo D, et al. Breast cancer screening with imaging: recommendations from the Society of Breast Imaging and the ACR on the use of mammography, breast MRI, breast ultrasound, and other technologies for the detection of clinically occult breast cancer. Journal of the American College of Radiology : JACR. 2010; 7: 18-27. doi:10.1016/j.jacr.2009.09.022.

50. Dershaw DD. Mammography in patients with breast cancer treated by breast conservation (lumpectomy with or without radiation). AJR Am J Roentgenol. 1995; 164: 309-16. doi:10.2214/ajr.164.2.7839960.

51. Orel SG, Fowble BL, Solin LJ, Schultz DJ, Conant EF, Troupin RH. Breast cancer recurrence after lumpectomy and radiation therapy for early-stage 
disease: prognostic significance of detection method. Radiology. 1993; 188: 189-94.

52. Bevers TB, Anderson BO, Bonaccio E, Buys S, Daly MB, Dempsey PJ, et al. NCCN clinical practice guidelines in oncology: breast cancer screening and diagnosis. Journal of the National Comprehensive Cancer Network : JNCCN. 2009; 7: 1060-96.

53. Mainiero MB, Lourenco A, Mahoney MC, Newell MS, Bailey L, Barke LD, et al. ACR Appropriateness Criteria Breast Cancer Screening. Journal of the American College of Radiology : JACR. 2013; 10: 11-4. doi:10.1016/j.jacr.2012.09.036.

54. Berg WA, Zhang Z, Lehrer D, Jong RA, Pisano ED, Barr RG, et al. Detection of breast cancer with addition of annual screening ultrasound or a single screening MRI to mammography in women with elevated breast cancer risk. JAMA. 2012; 307: 1394-404. doi:10.1001/jama.2012.388.

55. Korpraphong $\mathrm{P}$, Tritanon $\mathrm{O}$, Tangcharoensathien $\mathrm{W}$, Angsusinha $\mathrm{T}$, Chuthapisith S. Ultrasonographic characteristics of mammographically occult small breast cancer. Journal of breast cancer. 2012; 15: 344-9. doi:10.4048/jbc.2012.15.3.344

56. Mahoney MC, Newell MS. Screening MR imaging versus screening ultrasound: pros and cons. Magnetic resonance imaging clinics of North America. 2013; 21: 495-508. doi:10.1016/j.mric.2013.04.001.

57. Drukteinis JS, Gombos EC, Raza S, Chikarmane SA, Swami A, Birdwell RL. MR imaging assessment of the breast after breast conservation therapy: distinguishing benign from malignant lesions. Radiographics : a review publication of the Radiological Society of North America, Inc. 2012; 32: 219-34. doi:10.1148/rg.321115016.

58. Liberman L, Morris EA, Dershaw DD, Abramson AF, Tan LK. MR imaging of the ipsilateral breast in women with percutaneously proven breast cancer. AJR Am J Roentgenol. 2003; 180: 901-10. doi:10.2214/ajr.180.4.1800901.

59. Destounis S, Morgan R, Arieno A, Seifert P, Somerville P, Murphy P. A review of breast imaging following mastectomy with or without reconstruction in an outpatient community center. Breast cancer. 2011; 18: 259-67. doi:10.1007/s12282-011-0287-0.

60. Quinn EM, Coveney AP, Redmond HP. Use of magnetic resonance imaging in detection of breast cancer recurrence: a systematic review. Ann Surg Oncol. 2012; 19: 3035-41. doi:10.1245/s10434-012-2341-3.

61. Barnsley GP, Grunfeld E, Coyle D, Paszat L. Surveillance mammography following the treatment of primary breast cancer with breast reconstruction: a systematic review. Plast Reconstr Surg. 2007; 120: 1125-32. doi:10.1097/01.prs.0000279143.66781.9a.

62. Schnall MD, Blume J, Bluemke DA, DeAngelis GA, DeBruhl N, Harms S, et al. Diagnostic architectural and dynamic features at breast MR imaging: multicenter study. Radiology. 2006; 238: 42-53. doi:10.1148/radiol.2381042117.

63. Saslow D, Boetes C, Burke W, Harms S, Leach MO, Lehman CD, et al. American Cancer Society guidelines for breast screening with MRI as an adjunct to mammography. CA Cancer J Clin. 2007; 57: 75-89.

64. Brennan S, Liberman L, Dershaw DD, Morris E. Breast MRI screening of women with a personal history of breast cancer. AJR Am J Roentgenol. 2010; 195: 510-6. doi:10.2214/AJR.09.3573

65. Helvie MA, Bailey JE, Roubidoux MA, Pass HA, Chang AE, Pierce LJ, et al. Mammographic screening of TRAM flap breast reconstructions for detection of nonpalpable recurrent cancer. Radiology. 2002; 224: 211-6.

66. Rosselli Del Turco M, Palli D, Cariddi A. It is now the age to define the appropriate follow-up of primary breast cancer patients. Journal of clinical oncology : official journal of the American Society of Clinical Oncology. 1994; 12: 1996-7.

67. Collins RF, Bekker HL, Dodwell DJ. Follow-up care of patients treated for breast cancer: a structured review. Cancer treatment reviews. 2004; 30: 19-35. doi:10.1016/S0305-7372(03)00141-5.

68. Evangelista L BZ, Vinante L, Lotti G, Muzzio PC. Tumour Markers and Molecular Imaging with FDG PET/CT in Breast Cancer: Their Combination for Improving the Prediction of Disease Relapse. In: CS H, editor. Positron Emission Tomography - Current Clinical and Research Aspects: InTech; 2012.

69. Gallowitsch HJ, Kresnik E, Gasser J, Kumnig G, Igerc I, Mikosch P, et al. F-18 fluorodeoxyglucose positron-emission tomography in the diagnosis of tumor recurrence and metastases in the follow-up of patients with breast carcinoma: a comparison to conventional imaging. Investigative radiology. 2003; 38: 250-6. doi:10.1097/01.RLI.0000063983.86229.f2

70. Suarez M, Perez-Castejon MJ, Jimenez A, Domper M, Ruiz G, Montz R, et al. Early diagnosis of recurrent breast cancer with FDG-PET in patients with progressive elevation of serum tumor markers. The quarterly journal of nuclear medicine : official publication of the Italian Association of Nuclear Medicine. 2002; 46: 113-21.

71. Bar-Shalom R, Yefremov N, Guralnik L, Gaitini D, Frenkel A, Kuten A, et al. Clinical performance of PET/CT in evaluation of cancer: additional value for diagnostic imaging and patient management. Journal of nuclear medicine : official publication, Society of Nuclear Medicine. 2003; 44: 1200-9.

72. Champion L, Brain E, Giraudet AL, Le Stanc E, Wartski M, Edeline V, et al. Breast cancer recurrence diagnosis suspected on tumor marker rising: value of whole-body 18FDG-PET/CT imaging and impact on patient management. Cancer. 2011; 117: 1621-9. doi:10.1002/cncr.25727.

73. Grassetto G, Fornasiero A, Otello D, Bonciarelli G, Rossi E, Nashimben O, et al. 18F-FDG-PET/CT in patients with breast cancer and rising Ca 15-3 with negative conventional imaging: a multicentre study. European journal of radiology. 2011; 80: 828-33. doi:10.1016/j.ejrad.2010.04.029.
74. Fueger BJ, Weber WA, Quon A, Crawford TL, Allen-Auerbach MS, Halpern BS, et al. Performance of 2-deoxy-2-[F-18]fluoro-D-glucose positron emission tomography and integrated PET/CT in restaged breast cancer patients. Molecular imaging and biology : MIB : the official publication of the Academy of Molecular Imaging. 2005; 7: 369-76. doi:10.1007/s11307-005-0013-4.

75. Aukema TS, Rutgers EJ, Vogel WV, Teertstra HJ, Oldenburg HS, Vrancken Peeters MT, et al. The role of FDG PET/CT in patients with locoregional breast cancer recurrence: a comparison to conventional imaging techniques. European journal of surgical oncology : the journal of the European Society of Surgical Oncology and the British Association of Surgical Oncology. 2010; 36: 387-92. doi:10.1016/j.ejso.2009.11.009.

76. Dirisamer A, Halpern BS, Flory D, Wolf F, Beheshti M, Mayerhoefer ME, et al. Integrated contrast-enhanced diagnostic whole-body PET/CT as a first-line restaging modality in patients with suspected metastatic recurrence of breast cancer. European journal of radiology. 2010; 73: 294-9. doi:10.1016/j.ejrad.2008.10.031.

77. Filippi V, Malamitsi J, Vlachou F, Laspas F, Georgiou E, Prassopoulos V, et al. The impact of FDG-PET/CT on the management of breast cancer patients with elevated tumor markers and negative or equivocal conventional imaging modalities. Nuclear medicine communications. 2011; 32: 85-90. doi:10.1097/MNM.0b013e328341c898.

78. Radan L, Ben-Haim S, Bar-Shalom R, Guralnik L, Israel O. The role of FDG-PET/CT in suspected recurrence of breast cancer. Cancer. 2006; 107: 2545-51. doi:10.1002/cncr.22292.

79. Haug AR, Schmidt GP, Klingenstein A, Heinemann V, Stieber P, Priebe M, et al. F-18-fluoro-2-deoxyglucose positron emission tomography/computed tomography in the follow-up of breast cancer with elevated levels of tumor markers. Journal of computer assisted tomography. 2007; 31: 629-34. doi:10.1097/01.rct.0000284394.83696.42.

80. Schmidt GP, Baur-Melnyk A, Haug A, Heinemann V, Bauerfeind I, Reiser MF, et al. Comprehensive imaging of tumor recurrence in breast cancer patients using whole-body MRI at 1.5 and 3 T compared to FDG-PET-CT. European journal of radiology. 2008; 65: 47-58. doi:10.1016/j.ejrad.2007.10.021.

81. Shie P, Cardarelli R, Brandon D, Erdman W, Abdulrahim N. Meta-analysis: comparison of F-18 Fluorodeoxyglucose-positron emission tomography and bone scintigraphy in the detection of bone metastases in patients with breast cancer. Clinical nuclear medicine. 2008; 33: 97-101. doi:10.1097/RLU.0b013e31815f23b7.

82. Glendenning J, Cook G. Imaging breast cancer bone metastases: current status and future directions. Seminars in nuclear medicine. 2013; 43: 317-23. doi:10.1053/j.semnuclmed.2013.02.002.

83. Nakai T, Okuyama C, Kubota T, Yamada K, Ushijima Y, Taniike K, et al. Pitfalls of FDG-PET for the diagnosis of osteoblastic bone metastases in patients with breast cancer. European journal of nuclear medicine and molecular imaging. 2005; 32: 1253-8. doi:10.1007/s00259-005-1842-8.

84. Damle NA, Bal C, Bandopadhyaya GP, Kumar L, Kumar P, Malhotra A, et al. The role of 18 F-fluoride PET-CT in the detection of bone metastases in patients with breast, lung and prostate carcinoma: a comparison with FDG PET/CT and 99mTc-MDP bone scan. Japanese journal of radiology. 2013; 31: 262-9. doi:10.1007/s11604-013-0179-7.

85. Iagaru A, Young P, Mittra E, Dick DW, Herfkens R, Gambhir SS. Pilot prospective evaluation of $99 \mathrm{mTc}$-MDP scintigraphy, $18 \mathrm{~F} \mathrm{NaF}$ PET/CT, 18F FDG PET/CT and whole-body MRI for detection of skeletal metastases. Clinical nuclear medicine. 2013; 38: e290-6. doi:10.1097/RLU.0b013e3182815f64.

86. de Bock GH, Bonnema J, van der Hage J, Kievit J, van de Velde CJ. Effectiveness of routine visits and routine tests in detecting isolated locoregional recurrences after treatment for early-stage invasive breast cancer: a meta-analysis and systematic review. J Clin Oncol. 2004; 22: 4010-8. doi:10.1200/JCO.2004.06.080

\section{Author Biographies}

Dr. Erika J. Schneble is a General Surgery resident at San Antonio Uniformed Services Health Education Consortium (SAUSHEC). She is currently spending her research year with the Cancer Vaccine Development Program at San Antonio Military Medical Center.

Dr. Matthew P. Shupe, DO graduated from A.T. Still University-Kirksville College of Osteopathic Medicine and completed residency in Internal Medicine at SAUSHEC. He is currently a Hematology/Oncology fellow at SAUSHEC.

Dr. Frederick L. Flynt is an Assistant Professor of Medicine at the Uniformed Services University of Health Sciences, School of Medicine, and the Associate Program Director for the Hematology/Oncology 
Fellowship program at the San Antonio Uniformed Services Health Education Consortium.

Dr Leonard Henry is an associate professor of surgery at Indiana University-South Bend and the director of surgical oncology at the Indiana University Health Goshen Center for Cancer Care.

Dr Alexander Stojadinovic is a Professor of Surgery and Professor of Medicine at the Uniformed Services University of the Health Sciences, Medical Director of the Bon Secours Cancer Institute and the Society of Surgical Oncology Designee to the AJCC

Dr. Nathan M. Shumway is an Assistant Professor of Medicine at the Uniformed University of Health Sciences Medical School and the Program Director for the Hematology/Oncology Fellowship program at the San Antonio Uniformed Services Health Education Consortium. He has active research interests in the area of breast cancer vaccines and immunology, communication skills training, and medical education. 